\title{
LA PRESENCIA DE JOSÉ CARLOS MARIÁTEGUI EN EL REPERTORIO AMERICANO (COSTA RICA, 1919-1959)
}

\author{
Roberta Fernández \\ University of Houston
}

\begin{abstract}
RESUMEN
En las revistas latinoamericanas de los años veinte, un núcleo de escritores publicaba sus trabajos sobre la interacción entre las artes internacionales y la política local, creando así un genuino espíritu fraterno y un diálogo internacional entre los formuladores de la conciencia nacional de una multitud de países. Las revistas dejaban el testimonio de un proceso intelectual en formación por medio de un gran número de materiales que coexistían simultáneamente en varias revistas. En este diálogo, dos de las voces más sobresalientes fueron la de José Carlos Mariátegui, director de Amauta y colaborador en muchas revistas de su época, entre ellas, el Repertorio Americano; y la de Joaquín García Monge, redactor infatigable del Repertorio Americano. Mariátegui contribuyó principalmente con tres discursos del Repertorio Americano: el americanismo continental, el papel de la enseñanza en la creación de la nación y el impacto del artista en la formulación de la cultura contemporánea. Aquí también se señala cómo los críticos de la época vieron a Mariátegui y sus contribuciones, especialmente su trabajo como director de Amauta.
\end{abstract}

\begin{abstract}
In Latin American magazines of the 20's, a group of writers published their works on the interaction of international arts and local politics, thus creating a genuine fraternal spirit and an international dialogue between the people who formulate the national conscience of a multitude of countries. These magazines are the testimony of an intellectual process in formation, through a great ammount of materials that coexisted in various magazines. In this dialogue, two of the most outstanding voices were that of José Carlos Mariátegui, director of Amauta and contributor to many magazines of his time, including Repertorio Americano, and that of Joaquín García Monge, untiring editor of Repertorio Americano. Mariátegui contributed mainly with three discourses of Repertorio Americano: continental Americanism, the role of teaching in the creation of the nation, and the impact of the artist in the formulation of contemporary culture. Here we also point out how the critics of that time saw Mariátegui and his contributions, specially his work as the director of Amauta.
\end{abstract}

\section{Introducción}

El periodismo literario de los años veinte nos provee una documentación de las luchas de los escritores contra las reglas de su época, y nos revela su compromiso con los acontecimientos 
políticos y estéticos del momento (Masiello, 3). Revistas como el Repertorio Americano de Costa Rica, Amauta del Perú, la Revista de Avance de Cuba y Babel de Buenos Aires entre muchas más, se enfrentaban con los movimientos internacionales en las artes y las letras para enfatizar su compromiso con la política y la cultura local. En estas revistas, un núcleo de escritores publicaba sus trabajos sobre la interacción entre las artes internacionales y la política local, creando así un genuino espíritu fraterno y un diálogo internacional entre los formuladores de la conciencia nacional de una multitud de países. A la vez, las revistas dejaban el testimonio de un proceso intelectual en formación por medio de un gran número de materiales que coexistían simultáneamente en varias revistas. En este diálogo, dos de las voces más sobresalientes fueron la de José Carlos Mariátegui, director de Amauta y colaborador en muchas revistas de su época (entre ellas, el Repertorio Americano ) y la de Joaquín García Monge, redactor infatigable del Repertorio Americano.

Este estudio va a concentrarse en la relación profesional que hubo entre dos de los grandes promotores de la prensa periodística en la América Latina: Mariátegui y García Monge. Primero se va a presentar información biográfica acerca del director costarricense; luego veremos la manera en que la presencia de Mariátegui se hizo palpable en el Repertorio Amt ricano, enfocándonos en la contribución que él hizo a varios de los discursos que García Monge promovía en su revista: el americanismo continental, el papel de la enseñanza en la creación de la nación y el impacto del artista en la formulación de la cultura contemporánea. Finalmente, señalaremos cómo los críticos de la época vieron a Mariátegui y sus contribuciones, especialmente su trabajo como director de Amauta.

\title{
1. Joaquín García Monge y su Repertorio Americano
}

En una rara ocasión en 1921, cuando don Joaquín tenía cuarenta años, se presentó a sí mismo, con evidente desgano:

\begin{abstract}
Yo no tengo biografía. Aún no he hecho nada que merezca recordarse. Hace como cuarenta años nací [en 1881] en Desamparados, en donde pasé al lado de mi madre la niñez y la adolescencia. Hice los estudios primarios y los secundarios en el Liceo de Costa Rica. Un día de tantos se le ocurrió a don Justo A. Facio mandarme a Chile, a hacer estudios pedagógicos. Pasé en aquel país tres años, de 1901 a 1904. Volví aquí, con carrera de profesor, que a saltos y brincos he ido recorriendo. En el camino me ha tocado ser Director de la Escuela Normal y Secretario de Instrucción Pública. En ninguna parte he hecho nada. Ahora me refugio en la Biblioteca, sabe Dios hasta cuando, mientras llega la hora de morir, que es la mejor. Hace como diez años me casé. Tengo un hijo que es toda mi ilusión. Si en algo he servido al país es con las ediciones. La "Colección Ariel," "El Convivio" y el Repertorio Americano anduvieron y andan por el mundo, diciendo que en esta minúscula Costa Rica ha sido posible crear un hogar intelectual, una fundación de fraternidad espiritual entre las gentes de habla castellana. Por este lado y por el de la pequeña obra literaria que haya realizado (El moto, La mala sombra, etc.) tal vez me recuerden los venideros en la familia y en la patria ("Maestros indoiberos: García Monge, 85).
\end{abstract}

En realidad, García Monge recibió multiples honores. En 1919, el año en que fundó su revista, fue nombrado director de Secretarías de Educación de Costa Rica, lo que sin duda tuvo gran influencia en la presentación de uno de los temas más frecuentes en la revista: la pedagogía nacional. En 1920 ingresó a la Biblioteca Nacional como Director, cargo que desempeñó durante dieciséis años. Como escritor, fue reconocido como el novelista que introdujo el 
costumbrismo a Costa Rica a través de sus tres novelas, El moto (1900), Hijas del campo (1901) y Abnegación (1902). Entre 1906 y 1916, publicó su “Colección Ariel”, colección económica de escogida literatura internacional, antigua y moderna, en folletos de treinta y dos páginas. De 1917 hasta 1920, publicó la serie de Autores Costarricenses; y en 1925, inició una serie de literatura infantil, La Edad de Oro.

En 1939, El Nacional, en México, D.F., señaló el impacto que las colecciones de García Monge habían tenido en el desarrollo de la literatura iberoamericana.

\begin{abstract}
Va desde 1906, con la fundación de la Editorial "Ariel", auspicioso nombre, el maestro costarricense, popularizando en síntesis baratas a Ingenieros, a Rodó, a Lugones, a los principales fanales del pensar racial, iniciaba brillantemente sus servicios a todas las gentes de habla española. En las subsiguientes ediciones de "El Convivio", bajo los signos de Bolívar, Almafuerte, Varona, Martí, Hostos, hizo el favor, maravilloso siempre y más en aquellos tiempos, de prestar la magnavoz mágica de los tipos de imprenta, a la vez a la más pura y caudalosa tradición democrática y a los nuevos escritores cuyas obras permanecían aún casi en el secreto de la cábala: así empezamos todos a admirar y querer, por su intermedio, a Brenes Mesén, Chacón y Calvo, Isaías Gamboa, Cornelio Hispano, López de Meza, Julio Torri, Magallanes Moure, Alberto Ureta, Vaz Ferreira, Rafael Cardona, y a la teoría de poetisas a cuyo frente se adelantaba entre un rasgado malva de auroras, la rodilla de diosa de Delmira Agustini ("Maestros indoiberos: García Monge": 85-6).
\end{abstract}

Entre los numerosos honores internacionales que recibió don Joaquín se incluyen la Insignia de la Orden Mexicana del Águila Azteca (1940), el Diploma de Gratitud Nacional del Ecuador (1949) y la Gran Cruz de la Orden El Sol del Perú (1958). En 1944, Columbia University en Nueva York le otorgó el premio Mary Moors Cabot por sus contribuciones al periodismo continental. Para esa ocasión escribió pero no pronunció su idea de la función social del arte:

Para mí como editor del Repertorio, aunque tienen un valor en sí mismas las artes, las letras y las ciencias, ellas no solamente son creaciones del hombre, sino que deben ponerse al servicio de las sociedades. Se esculpe, se escribe, y se pinta y se graba para hacernos expresivos de la grandeza que llevamos con nosotros y estimular la grandeza aún no descubierta, quizás, en quienes contemplan la obra ejecutada. La belleza posee la magia de hermosear y mejorar a los hombres (Citado por Ferrer, xlvi).

Joaquín García Monge pensaba que lo esencial de su Repertorio Americano estaba en la búsqueda de lo 'americano', lo continental. Fue por eso que le dio a su revista el mismo nombre del viejo Repertorio Americano que Andrés Bello fechó el $1^{\circ}$ de julio de 1826 en Londres. No sudamericano, no hispanoamericano sino americano. Nos recuerda el escritor R. Brenes Mesén (1927: 93) que Bello quería "revelar a las naciones europeas la existencia de las nacientes sociedades americanas animadas por un mismo amor de las artes y de las ciencias para quienes aquella obra benemérita se realizaba". Compara este escritor el papel de los dos Repertorios: "Don Andrés Bello contempla las diversas naciones hispanoamericanas en la comunidad de sus necesidades de educación, aspiraba a ilustrarlas por igual modo y a representarlas ante Europa en cuanto de mejor hacían, poseían, y ambicionaban. El Repertorio de hoy se ha consagrado a formar, a afirmar y a desenvolver la conciencia de la raza revelando a cada entidad del conjunto su comunidad de intereses espirituales con el todo en el Continente y, si es posible, con la raza fuera de él. El Repertorio es un órgano de la incipiente conciencia de la raza en el Continente" (Brenes Mesén 1927: 93). 
El segundo Repertorio Americano nació en San José, Costa Rica, el 1ero de septiembre de 1919 en casa de Joaquín García Monge, donde se publicó como semanario de ocho pliegos, dieciséis páginas hasta 1959. Don Joaquín falleció en 1958 pero sus admiradores, dirigidos por su hijo, Eugenio García Carrillo, publicaron un número póstumo en 1959 en homenaje al ilustre hombre. Con este número póstumo, la revista cerró después de treinta y nueve años de actividad en los que se publicaron 1.186 números. En octubre de 1974, se inició otro Repertorio Americano, patrocinado por la Universidad Nacional de Heredia, Costa Rica; éste no se identifica estrictamente con el Repertorio Americano de García Monge, aunque sí lo considera su hermano mayor.

Durante su larga trayectoria, la revista de García Monge hizo el papel que hasta cierto punto haría hoy día el chat room en la Internet. Allí iban los intelectuales de su época para informarse de lo que estaba pasando en el mundo de la política y las letras, y en la cultura en general. Max Henríquez Ureña comparó la función del Repertorio Americano a la de un clearing house. "El Repertorio Americano, vocero y acervo de la cultura continental, era un medio de comunicación y de información para cuantos quisieran conocer y apreciar el movimiento de las ideas en la América española: era algo así como un clearing house de la producción intelectual hispanoamericana" (Henríquez Ureña 1959: 88). Dejó Henríquez Ureña su recuerdo de cómo don Joaquín hacía su trabajo de compilador. "A su mesa llegaban periódicos y libros de todas partes, en copiosa profusión. García Monge, tijera en mano, seleccionaba, día tras día, lo que pudiera ser digno del Repertorio Americano" (Henríquez Ureña 1959: 88).

Con el intento de promover un diálogo acerca de los movimientos políticos y culturales de su tiempo, García Monge guardaba lugar en cada número de su revista para las cartas que recibía de las cuatro esquinas del mundo hispano. A través de estas cartas, Sandino mantenía a los lectores al día acerca de su lucha en Nicaragua. Vasconcelos propagaba sus ideas acerca del nacionalismo mexicano. Gabriela Mistral escribía de sus viajes como educadora del continente. Haya de la Torre y Magda Portal promovían las ideas del APRA. Unamuno, Barbusse, Lugones, Quiroga, Reyes y muchos otros pensadores intercambiaban ideas acerca del americanismo y de los acontecimientos locales en los que participaban. A través de la sección "Tablero" y de la columna "Un estante de obras escogidas", se mantenían al día las direcciones de sus colaboradores peripatéticos y se anunciaban los libros recién publicados que lectores, autores y casas editoriales le mandaban a García Monge. Uno de sus muchos admiradores lo nombró "el preclaro promotor de cultura" y comparó su misión con la de Sarmiento: "Educar es civilizar. ... don Joaquín se ha transformado en el insuperable confidente y colaborador de quienes experimentan la obsesión purificadora de fortalecer y sublimar la conciencia hispano-americana" (Leguía 1926: 261).

Después de la muerte de don Joaquín, Luis Alberto Sánchez describió el papel que la revista hacía como tribuna política: "No tuvo Sandino mejor tribuna que el "Repertorio"; ni Guiteras, ni Baltasar Brum, ni Carlos Vicuña Fuentes, ni Lázaro Cárdenas. Don Joaquín escribía poco, pero mantenía abierto el ojo y lista la mano para escoger siempre lo mejor, adobándolo de vez en cuando con uno que otro comentario salado y breve de su generosa pluma" (Sánchez 1959: 87).

Pero, es importante recordar que el desarrollo de la conciencia continental que se formulaba en el Repertorio Americano no se enfocaba únicamente en cuestiones políticas. García Monge, como José Carlos Mariátegui y otros colaboradores, pensaba que entre los formuladores de la conciencia nacional se encontraban los artistas, quienes interpretaban, inspiraban 
y guiaban a su pueblo. Por eso, García Monge concebía que "las artes dan la tónica de una época y la expresan cabalmente" (Ferrer, xlii).

En 1929, en el décimo aniversario del Repertorio Americano, L. N. Nieto Caballero elogió no sólo el papel de la revista costarricense sino también el esfuerzo de su director:

El Repertorio es como una vasta tertulia. Cada cual dice sus sueños y sus experiencias y oye a los demás con gusto. Gracias a él nos conocemos muchos que vivimos separados por millares de leguas. Circula más y se lee más en toda América que una revista de mayores dimensiones. Escritores magníficos de todos nuestros pueblos lo leen gratuitamente. Es una obra bella, intensa, y como ninguna otra, desinteresada. Generosa; además, inconcebible casi, porque ta realiza un hombre pobre. Es un soñador, es un individuo sin ambiciones que goza con que todo lo que él hace refluya sobre Costa Rica. Tal vez, no hay en toda la América Latina una publicación más digna de apoyo (Nieto Caballero 1929: 234).

Luego, en 1940, en la ocasión del vigésimo aniversario de la revista, Magda Portal, frecuente colaboradora peruana, describió el trabajo de don Joaquín y de su revista de la siguiente manera:

A donde quiera que uno vaya le sigue el mensaje fraterno de Repertorio. Con una memoria extraordinaria García Monge recuerda los nombres de sus más distantes amigos para enviarles su palabra y la de los demás, con constancia de destino, y con una suerte de fidelidad que asombra y conmueve. [...]

Veinte años de obra, sin ningún estímulo exterior, salvo las cartas de lọ amigos; sin colaboraciones económicas, ni subvenciones oficiales -Repertorio ha sufrido persecuciones y ha sido sometido a juicio por sus campañas- sin suscripciones numerosas que solventen la edición, hecho a base de esfuerzo personal de García Monge, que ama su semanario con amor de padre, esta alta tribuna del pensamiento libre continúa batiendo el record de las de su género en América (Portal 1940).

Jesús Silva Herzog, director de Cuadernos Americanos, también nos ha dejado un recuerdo del homenaje que su revista le hizo a García Monge en el número de enero-febrero de 1953. En éste, colaboraron treinta y cinco hombres de letras conotados de dieciséis países del Continente y ree españoles asilados en México.

A García Monge deberíamos proclamarlo el mejor ciudadano de nuestra América; el mejor ciudadano en veinte naciones que luchan por conquistar para siempre la libertad y la justicia social, por marchar hacia adelante y cumplir el hermoso destino señalado por los dioses. Él ha consagrado a esa lucha sus más nobles afanes en su ya larga y laboriosa existencia.

Cuadernos Americanos se honra al honrar a su hermano mayor: el Repertorio Americano. Su hermano en la defensa de los pueblos nuestros, víctimas de la codicia del mercader; su hermano, en fin, en la angustia y en los sueños.

Y yo, desde mi México, tierra de libertad y refugio de perseguidos, violando la distancia estrecho a don Joaquín la mano en actitud emocionada y fraternal (Citado por Cardona Peña, lx-lxi).

Con su gran sentido de misión periodística, García Monge tomó interés en el trabajo de José Carlos Mariátegui, cuya presencia en la revista costarricense se fue haciendo evidente desde 1925 a causa de sus propias contribuciones a la revista y por lo que otros colaboradores escribían acerca de él y de su trabajo. 


\section{Mariátegui, el Repertorio Americano y el discurso del nacionalismo continental}

En 1919, Mariátegui viajó a Europa con el cargo de periodista, representando el periódico El Tiempo; la realidad era que había sido exiliado por el nuevo presidente, Augusto B. Leguía. El 1ero de septiembre de ese año, Joaquín García Monge inauguró el Repertorio Americano con un número en que se destacaba un cuento de Leopoldo Lugones y unos poemas de Juảna de Ibarbourou. A primera vista, el Repertorio Americano daba la impresión de que iba a ser una revista modernista, pero para el número octavo (10 de diciembre, 1919), cambió de tono y se enfocó en la enseñanza, en el papel de la escuela normal de Costa Rica, revelando de esta forma uno de los temas de más interés de su director, especialmente ese año cuando acababa de ser nombrado director de la Secretaría de Educación. A través de los años, el $R e$ pertorio Americano animó a sus colaboradores a que participaran en el discurso sobre el papel que la enseñanza tiene en la cultura nacional de cada país y, por ende, en la formulación de una cultura continental.

Al empezar su tercer año (el 5 de septiembre de 1921), la revista se estableció definitivamente como semanario; y para 1923, año en que regresa Mariátegui de Europa, contaba con la colaboración de los activistas y la de los escritores y pensadores más sobresalientes de la época: Gabriela Mistral, José Vasconcelos, Pedro Henríquez Ureña, Miguel de Unamuno, Alfonso Reyes, Magda Portal, Víctor Raúl Haya de la Torre, Víctor Andrés Belaunde, Alfonsina Storni y Juan Ramón Jiménez, entre muchos más. Ya para 1925, cuando Mariátegui comenzó a colaborar con la revista, el Repertorio Americano era reconocido como uno de los grandes mediadores de la cultura continental.

Por su parte, Mariátegui también se había establecido como una de las voces importantes en la política y la vida cultural de su país. Para entonces, Mariátegui ya tenía un fuerte sentido de su propia participación en la historia contemporánea, especialmente como periodista y director de revistas, i.e., Nuestra Época (1918) y La Razón (1919). Entre 1920 y 1922 publica crónicas y artículos en El Tiempo acerca de sus experiencias en Europa en las que revela su gran pasión por la prensa periodística, ya demostrada en parte por la interacción personal que había establecido en 1919 en París con Henri Barbusse, fundador y director de la revista francesa Clarté; y en 1923 en Berlín con Herwarth Walden, director de la revista alemana Der Sturm. También deja documentada su gran admiración por Antonio Gramsci, director de L'Ordine Nuovo.

Recién llegado al Perú de Europa, Mariátegui fue invitado por Haya de la Torre a participar en el movimiento estudiantil de la Universidad Popular González Prada. Más tarde, en 1923, cuando Leguía exilia a Haya de la Torre, Mariátegui asume la dirección de la revista Claridad, órgano de la Universidad Popular González Prada (Klaiber 708-709). Poco después comienza a contribuir con regularidad en las revistas peruanas Mundial y Variedades. En 1925, Mariátegui auto-publica su primer libro, La escena contemporánea, una recopilación de las conferencias que había dictado en la Universidad Popular González Prada sobre la política y la vida cultural europea que él mismo había visto de cerca.

Ese año también se enfrenta por primera vez con los temas de la nacionalidad peruana. Publica "Hacia el estudio de los problemas peruanos" (Mundial, 10 de julio, 1925), su nrimer artículo sobre la realidad nacional de su país; dos meses más tarde, publica "El ri 
el alma del Tawantinsuyo" (Mundial, 11 de septiembre, 1925), su primer trabajo sobre el indigenismo político en donde comenta sobre De la vida incaica de Luis Valcárcel. En otro artículo, "El indio de la República" (Mundial, 25 de septiembre, 1925), se refiere al trabajo indianista de Enrique López Albujar y por primera vez se refiere al indigenismo literario.

Fue durante esta época de transición personal y política que la presencia de Mariátegui comienza a hacerse evidente en el Repertorio Americano. Un año antes de que Mariátegui fundara Amauta, dos de los grandes directores de la prensa periodística americana establecen una gran amistad por medio de sus revistas. Esta correspondencia se basa en un respeto mutuo por el trabajo que cada uno realiza en su propio país.

\subsection{El discurso de la cultura continental}

Para 1925 el discurso del nacionalismo continental era uno de los más vigentes en el Repertorio Americano. Ese año, uno de sus primeros artículos acerca del americanismo intelectual fue "Política americana" (30 de marzo, 1925) de Leopoldo Lugones. Como representante argentino a la Sociedad de Naciones, Lugones reacciona a una celebración del centenario de Ayacucho, que acababa de tomar lugar en Lima, donde el iberoamericanismo se había promovido. Según Lugones, los representantes reunidos en Lima habían dejado la impresión de que el "iberoamericanismo ... era una mera expresión" (1925: 66).

Para animar el dialógo acerca del iberoamericanismo, García Monge publicó una serie de cartas y artículos dirigidos a Lugones en los que se nota la influencia del arielismo. Este se ve claramente en los comentarios de uno de los promotores más activos del nacionalismo literario americano, el peruano Edwin Elmore, quien en esos momentos se dedicaba a promover un Congreso Iberoamericano de Intelectuales. Para él, "La América de Próspero -aquella vaga y bellísima Utopia de hace veinte años- es hoy realidad magnífica" (30 de marzo, 1925: 69).

Carta tras carta y manifiesto tras manifiesto, Elmore declara su entusiasmo por un movimiento que una a la América Ibérica (en oposición a la América del Norte). Sugiere que su América había sido llamada por el Próspero de Rodó a superarse moralmente, y declara que "Es entendido: 1. Que la unión espiritual de los pueblos iberoamericanos así bosquejada, no se considera sino como un paso previo hacia la gran unión universal que todos los hombres de buena fe y de buena voluntad anhelan; 2. (...) que la obra iniciada con este movimiento, ya vigoroso en el Continente, no repudia sino que más bien solicita la cooperación de todos los hombres" (1925: 71).

En reacción a la retórica de Elmore y de otros escritores, Mariátegui publicó un artículo en Mundial titulado “Existe un pensamiento hispano-americano?”. Poco después, García Monge lo reimprime en la página principal del número 6 de julio, 1925 del Repertorio Americano, y explica en una nota cómo el trabajo del escritor peruano cayó en sus manos: "En carta de Lima, mayo 13 de 1925, nos dice un amigo: 'Le envío, pues, lo que ahora tengo a la mano, que, como Ud. verá, no carece de interés- un artículo de José Carlos Mariátegui, joven escritor que une (cosa rara en estos tiempos) la honradez y la lealtad al talento" (1925: 258).

En este, su primer artículo en el Repertorio Americano, Mariátegui desafía a los intelectuales a que conceptualicen su futuro congreso en términos más globales y menos utópicos. Hasta se enfrenta con uno de los promotores del americanismo más respetados-José 
Vasconcelos. Advierte Mariátegui: "La fe de América en el porvenir no necesita alimentarse de una artificiosa y retórica exageración de su presente. Está bien que América se crea predestinada a ser el hogar de la futura civilización. Está bien que diga: 'por mi raza hablará el espíritu'. Está bien que se considere elegida para enseñar al mundo una verdad nueva. Pero no que se suponga en vísperas de reemplazar a Europa ni que declare ya fenecida y tramontada la hegemonía intelectual de la gente europea" (1925: 257-8).

Pausemos aquí para notar otras palabras de Mariátegui, escritas ese mismo año en su reseña de Indología de Vasconcelos (la que no se publica en el Repertorio Americano hasta quince años más tarde) en las que nos recuerda que la promesa de Vasconcelos de una futura raza cósmica era un concepto demasiado utópico y que la idea de la América Hispánica era un fantasma de una retórica política e intelectual.

La ausencia que los espíritus de la nueva generación tenemos que constatar con un poco de tristeza y desencanto en la obra de Vasconcelos, es la ausencia de un sentido más agudo y despierto de lo presente. La época reclama un idealismo más práctico, una actitud más beligerante. Vasconcelos nos acompaña fácil y generosamente a condenar el presente, pero no a entenderlo ni utilizarlo. Nuestro destino es la lucha más que la contemplación (20 de abril, 1940: 165).

$\mathrm{Al}$ contestar su propia pregunta, ¿Existe un pensamiento característicamente hispanoamericano?, Mariátegui dice que le parece evidente que en la cultura de Occidente se pueda contar con "la existencia de un pensamiento francés, de un pensamiento alemán..." (1925: 258). Pero no le parece "igualmente evidente, en el mismo sentido, la existencia de un pensamiento hispano-americano. Todos los pensadores de nuestra América se han educado en una escuela europea. No se siente en su obra el espíritu de la raza" (1925: 258). Además, dice Mariátegui, por lo general los formuladores del americanismo estaban ignorando al mundo indígena. Por lo tanto, sus proyecciones para el futuro de Ibero-América se basaban en una premisa errónea. Si un congreso de intelectuales iba a llevarse a cabo eficazmente, afirma Mariátegui, sus promotores tendrían que dejar su cómoda ficción al lado y plantearse con la realidad de toda América.

Mariátegui termina su artículo en tono positivo, asegurando a los jóvenes argentinos que merecen el liderazgo del movimiento americanista por el espíritu creativo que demuestran. Al sugerir que en la sección argentina alienta un espíritu moderno y una voluntad renovadora que les da a ellos el derecho de dirigir el movimiento, Mariátegui alude a uno de sus conceptos básicos: que la ruptura con el pasado decadente la harán "los hombres nuevos" de criterio creativo y crítico.

Siendo su intención promover el diálogo acerca del Congreso de Intelectuales que su revista apoyaba, García Monge también publica la respuesta que Edwin Elmore le hizo a Mariátegui. Aquí, Elmore confiesa que cuando él y las personas con quienes mantiene correspondencia (Varona, Vasconcelos, Zum Felde, Roig, Mañach, entre otros) habían originado la idea de un congreso, en realidad no habían hablado de coordinación o de organización del pensamiento hispano-americano" (1925: 259). Continúa Elmore, "[H]emos tenido en mente motivos y significaciones de mucho menor alcance que el que ahora se atribuye a nuestras palabras. Pero la interpretación que se les da no es, por eso, menos exacta" (1925: 259). A pesar de esta concesión, Elmore insiste en que para él sí hay una respuesta afirmativa para la pregunta de Mariátegui.

Por eso, Elmore ignora el desafío que su compatriota le había hecho a que tomara en cuenta cuestiones de raza y clase que hasta ese momento no habían entrado al diálogo del americanismo continental, e insiste en que: 
1) Existe un pensamiento hispánico.

2) Existe una cultura hispánica.

3) Existe un concepto y un sentimiento hispánicos de la vida.

4) Existen las bases fundamentales, históricas, étnicas, económicas, políticas, sociales, geográficas, y principalmente ideales, para la creación de una cultura hispano-americana (259).

Otra perspectiva acerca del iberoamericanismo se encuentra en un artículo del español Luis Araquistain, titulado "Organización de la cultura hispánica" (1925: 260-262) que aparece en el mismo número de la revista. Responiendo a Lugones, Araquistain propone que "la lengua es el más poderoso instrumento de comunidad humana" (260). Por consiguiente, "por debajo de nuestros diferentes ideales hay en los que la hablan una raza común" (260). Sugiere actividades específicas que ayuden a crear una infra-estructura para el iberoamericanismo, como "organismos comunes-revistas, exposiciones, congresos, universidades" (261).

La dinámica que se ha visto aquí en la interacción entre cuatro escritores -Lugones, Mariátegui, Elmore, y Araquistain- continúa durante el año 1925 y en años siguientes. Por medio de las páginas del Repertorio Americano, otros escritores y pensadores contribuyeron al discurso del americanismo continental, entre ellos, José Vasconcelos, Gabriela Mistral, Víctor Raúl Haya de la Torre, Manuel Ugarte, Víctor Andrés Belaunde, Joaquín Edwards Bello, Daniel de la Vega, Diego Rivera, y el mismo José Carlos Mariátegui. De esta forma, García Monge mantuvo viva en las páginas de su revista la producción del diálogo continental acerca del americanismo.

\subsection{Mariátegui y el papel de la enseñanza en la cultura continental}

En 1925 y en 1926, Mariátegui escribe cuatro artículos para el Repertorio Americano sobre la enseñanza como uno de los factores principales en la construcción de la cultura nacional. Mariátegui dice que responde a las siguientes preguntas que se habían hecho en un cuestionario del Repertorio Americano: ¿Cree Ud. que la enseñanza debe unificarse, con determinados propósitos raciales, en los países latinos de nuestra América? ¿Estima Ud. prudente que nuestra América Latina tome una actitud determinada en su enseñanza, ante el caso de los Estados Unidos del Norte?

García Monge solía dedicar una página de la revista a la enseñanza, bajo el titular "Qué hora es?...Sección destina a los encargados de la enseñanza pública en escuelas y colegios". Fue en esta sección en la que colocó tres de los artículos de Mariátegui. En el primer artículo, "La escuela laica" (7 de septiembre, 1925), Mariátegui se dirige al lema del grupo argentino que promovía la organización de la Unión Latino-Americana: "Extensión de la educación gratuita, laica y obligatoria y reforma universitaria integral". Sugiriendo que la educación gratuita, laica y obligatoria era el producto lógico del liberalismo y del capitalismo, Mariátegui examina la historia de la escuela laica. Influido por las ideas de Jorge Sorel, dice que la moral laica carece de los elementos espirituales indispensables para crear caracteres heroicos y superiores. Después de una presentación teórica y algo abstracta, Mariátegui llega a la conclusión de que la nueva generación iberoamericana no puede contentarse con una chata y gastada fórmula del ideario liberal. En términos sorelianos, Mariátegui apunta a los logros que 
se estaban ganando en México y en Rusia en el campo de la enseñanza, donde "la virtud renovadora y creadora de la escuela no reside en su carácter laico sino en su espíritu revolucionario. La revolución da ahí a la escuela su mito, su emoción, su misticismo, su religiosidad" (1925: 14).

El segundo artículo sobre "La libertad de la enseñanza" (9 de noviembre, 1925) sigue la misma estructura del primero: presentación de un lema propagado por un grupo activista, modelos de la historia europea en cuanto al tema, y la lección que-los jóvenes latinoamericanos pueden encontrar en la historia. Empieza diciendo que "la libertad de la enseñanza parece, a primera vista, el desideratum hacia el cual deben tender todos los esfuerzos renovadores" (136). Cumpliendo con su misión personal de mediador entre lo europeo y lo latinoamericano, Mariátegui presenta la historia de los compagnons de la Universidad Nueva en Francia, movimiento que nació en las trincheras con el propósito de la reforma total de la enseñanza. Pero, desde la perspectiva de Mariátegui, el movimiento no pudo lograr sus metas a causa de los principios moribundos de sus líderes y de las circunstancias históricas. Después de presentar otro ejemplo histórico -el de la reforma escolar en la Alemania de la post-guerra-para mostrar otro fracaso de la libertad en la enseñanza, Mariátegui concluye que esta libertad da la enseñanza no es, pues, "sino una ficción" (137). Termina dando consejos a "los hombres de vanguardia de Hispano-América", advirtiéndoles que "no deben enámorarse de un miraje. Deben hundir la mirada en la realidad. Vano es todo esfuerzo mental por concebir la escuela apolítica, la escuela neutral. La crisis de la enseñanza coincide universalmente con una crisis política" (1925: 137).

El tercer artículo, "La enseñanza y la economía" ( $1^{\circ}$ de marzo, 1926), revela la tendencia de Mariátegui a buscar la raíz de un problema social y la respuesta a ese problema en lo material. Empieza proponiendo que:

El problema de la enseñanza no puede ser bien comprendido si no es considerado como un problema económico y como un problema social. El error de muchos reformadores ha residido en su método abstractamente idealista, en su doctrina exclusivamente pedagógica. Sus proyectos han ignorado el íntimo engranaje que hay entre la economía y la enseñanza y han pretendido modificar ésta sin conocer las leyes de aquélla. Por ende, no han acertado a reformar nada sino en la medida que las leyes económicas sociales les han consentido (142).

Mariátegui enfoca su tesis de la base ecónomica de la enseñanza en el debate entre clásicos y modernos que, para él, no ha estado menos regido por el desarrollo capitalista que el debate entre conservadores y liberales en la política. Como había hecho en sus dos previos ensayos sobre la enseñanza, Mariátegui presenta ejemplos europeos de la lucha de los estudios clásicos y los modernos y luego llega a la respuesta que él sugiere como posible solución al problema: el establecimiento de la Escuela del Trabajo, propuesta por Pestalozzi y Froebel, como la enseñanza adecuada para una civilización de trabajadores. De nuevo Mariátegui termina con un consejo para la nueva generación hispano-americana, recordándoles que "el desarrollo de la economía hispano-americana exige una orientación práctica y realista en la enseñanza" (1926: 143).

García Monge le dio el espacio principal al cuarto artículo de Mariátegui, "Los maestros y las nuevas corrientes", situándolo en la primera página del número fechado el 8 de mayo de 1926. Basándose en la hipótesis de que hay un espíritu de clase que distingue y separa la enseñanza primaria de la enseñanza secundaria y superior, Mariátegui dice que el 
maestro primario se siente próximo al pueblo mientras que el maestro del liceo o de la universidad se siente dentro de la burguesía. Por eso, "la docencia secundaria y universitaria, tanto por su función como por su estructura, tiende a crear una burocracia conservadora" (273). Al contrario, el maestro primario hispano-americano procede del pueblo, o más específicamente, de la pequeña burguesía.

De nuevo, Mariátegui sigue la misma estructura que usó en los otros tres ensayos acerca de la enseñanza. Termina advirtiendo que "el modesto preceptor, el oscuro maestro del hijo del obrero y del campesino necesita comprender y sentir su responsabilidad en la creación de un orden nuevo" (274). Por consiguiente, los jóvenes latinoamericanos que aspiran a la creación de un mundo nuevo no pueden ser indiferentes a la dignidad del maestro de primaria quien fácilmente puede ser incorporado a la lucha de clase.

Por el lugar clave que García Monge le dio a esta serie de artículos mariateguianos, se entiende que había una correspondencia fuerte entre las premisas propuestas por su nuevo colaborador peruano y las ideas que él mismo promovía en las páginas de su revista. Mariátegui ofrece un conocimento amplio de la cultura europea contemporánea y una convicción de que hay que enfrentarse a los problemas americanos con respuestas prácticas y realistas. Esa misma convicción se verá más tarde en el cuarto ensayo de los Siete ensayos, "El proceso de la instrucción pública".

\section{Mariátegui, el Repertorio Americano y la crítica de las artes}

Entre el 5 de junio de 1926 y el 23 de septiembre de 1929, el Repertorio Americano publica dieciocho artículos de Mariátegui, la mayoría de ellos reseñas de libros. Después de la muerte de Mariátegui, se incluyen tres reseñas póstumas, y luego en conmemoración del décimo aniversario de su muerte, se publican otras dos reseñas, sobre Indología de Vasconcelos y sobre L'agonie du Christianism [sic] de Unamuno. En 1940, García Monge anota que estos dos artículos se habían entregado al Repertorio Americano en 1925, pero que hasta entonces habían quedado inéditos en el semanario.

Este conjunto de artículos confirma el papel de Mariátegui como uno de los primeros críticos literarios latinoamericanos, tesis comprobada por medio de sus trabajos sobre la literatura que forman parte de sus Obras completas: "El proceso de la literatura", el séptimo ensayo de los Siete ensayos de interpretación de la realidad peruana y los trabajos recopilados bajo los títulos El alma matinal y otras estaciones del hombre de hoy, El artista y la época, Signos y obras, y hasta cierto punto, Cartas de Italia. Todos estos son los libros en los que aparecen los artículos publicados en el Repertorio Americano, a los que ahora nos vamos a referir.

El 20 de octubre de 1926, Mariátegui le envió a García Monge una carta y un artículo titulado "El artista y la época" (25 de diciembre, 1926). En aquella, Mariátegui le hace saber a don Joaquín de la publicación de su nueva revista, Amauta, diciéndole que le gustaría intercambiar ejemplares de Amauta por ejemplares del Repertorio Americano: "Van diez números para establecer el intercambio con Repertorio. Como Amauta es mensual y se cotiza a 20 centavos oro, los diez números equivalen a cinco semanales de Repertorio" (380).

Cuenta Mariátegui que los comentarios de Diego Rivera sobre el arte proletario publicados en el Repertorio Americano (18 de septiembre, 1926) coincidían con los suyos: "El debate me parece sumamente interesante, y quiero terciar en él. Comparto absolutamente las 
ideas expresadas por Diego Rivera. Le adjunto un artículo "El artista y la época" que así lo demuestra. (En La escena contemporánea asoma la misma tesis.)" (380).

En la entrevista a la que se refiere Mariátegui, Rivera opina sobre el papel del nuevo arte en la sociedad capitalista:

No creo posible el desarrollo de un arte nuevo dentro de la sociedad capitalista, porque siendo el arte una manifestación social, aún en la aparición de un artista genial, mal puede un orden viejo producir un arte nuevo.

Además, siendo la obra de arte dentro del orden burgués un producto industrializado y financializable, sujeto a altas y bajas de precio como cualquier valor bancario o cualquiera acción industrial, cae bajo la ley de la oferta y la demanda con todas sus consecuencias agravadas por su calidad de producto mismo mental-sensitivo, estando el productor sujeto a la necesidad de hacer que su obra responda al gusto de sus consumidores para que ellos la paguen, aunque a veces el artista haga esto de un modo subconsciente (169).

Mariátegui agrega sus propios comentarios sobre el mismo tema en "El artista y ?? época", artículo en que claramente establece una correspondencia ideológica con Rivera. Esta reacción de Mariátegui a Rivera sirve como testimonio de un proceso cultural en formación y nos comprueba la dinámica que ocurría entre los colaboradores de la revista.

La burguesía quiere del artista un arte que corteje y adule su gusto mediocre. Quiere, en todo caso, un arte consagrado por sus peritos y tasadores. La obra de arte no tiene, en el mercado burgués un valor intrínseco sino su valor fiduciario. Los artistas más puros no son casi nunca los mejores cotizados. El éxito de un pintor depende, más o menos, de las mismas condiciones que el éxito de un negocio. Su pintura necesita uno o varios empresarios que la administren diestra y sagazmente. El renombre se fabrica a base de publicidad. Tiene un precio inasequible para el peculio del artista pobre (380).

También se refiere Mariátegui a "la dictadura de la prensa" que exalta al primer puesto a un artista mediocre y relega al último a un artista altísimo" (381).

Por su comprensión de la relación entre la celebridad que se establece a través de los medios de comunicación y la venta del arte, Mariátegui anticipa el análisis de los críticos del futuro, especialmente los de la Escuela de Frankfort acerca de la función y del poder de los medios de comunicación en la sociedad capitalista.

...la prensa no es sino uno de los instrumentos de la industria de la celebridad. La prensa no es responsable sino de ejecutar lo que los grandes intereses de esta industria decretan. Los managers del arte y de la literatura tienen en sus manos todos los resortes de la celebridad. En una época en que la celebridad es una cuestión de réclame, una cuestión de propaganda, no se puede pretender, además, que sea equitativa e imparcialmente concedida (381).

Esta entonces, aparentemente, es la perspectiva con la que Mariátegui se aproxima a la literatura que critica en el Repertorio Americano. Sus reseñas se pueden dividir en cinco categorías:

1) Sobre autores peruanos (Manuel González Prada, Magda Portal, y César Falcón);

2) Sobre artistas revolucionarias (Isadora Duncan, Louise Reissner, Magda Portal);

3) Sobre el realismo y los escritores rusos (Máximo Gorki, Fedor Gladkov);

4) Sobre autores europeos (Rainer María Rilke, Miguel de Unamuno);

5) Sobre autores americanos (José Vasconcelos, Waldo Frank). 
Contrario a la expectativa que uno podría tener de la visión crítica de Mariátegui por los comentarios que acabamos de ver en "El artista y la época, lo que más resalta en estas reseñas es la amplitud y la flexibilidad en su pensamiento en cuanto a la literatura. Si empezamos con El cemento de Fedor Gladkov vemos cómo Mariátegui la identifica como una potente novela realista, representante de la nueva literatura proletaria en Rusia, y ve en ella "un severo esfuerzo por crear una expresión del heroísmo revolucionario ..." (317). Al examinar otra novela rusa, Los Artamonov, Mariátegui describe a Máximo Gorki como el testigo de la revolución (139) y dice que Gorki "desmiente con esta novela que haya muerto el realismo" (142). Sin embargo, en la misma reseña dice que el superrealismo es una etapa de preparación para "el realismo verdadero, el infrarrealismo. "Había que soltar la fantasía, libertar la ficción de todas sus viejas amarras, para descubrir la realidad", comentario que podría servir como punto de partida para su crítica sobre el arte de vanguardia, tema que no trató Mariátegui en el $R e$ pertorio Americano.

De Nuestra América de Waldo Frank, dice que es "prueba concreta y elocuentemente la posibilidad de acordar el materialismo histórico con un idealismo revolucionario" (330). Sin embargo, relaciona el materialismo histórico de Frank con las palabras de Walt Whitman que aparecen en la portada de Nuestra América: "La grandeza real y durable de nuestros Estados será su religión". Y concluye que en Waldo Frank, "como en todo gran intérprete de la historia, la intuición y el método colaboran" (330). Declara que Jean Cristophe de Romain Rolland es la voz de la verdadera Francia y "[r]epresenta una protesta, una reacción contra un mundo de alma crepuscular y desencantada" (329). Lo que más admira en Rolland es su "espíritu fundamentalmente religioso" y dice que su trabajo espiritual es heroico (330). A Rainer María Rilke lo describe como "el lirismo puro" (78), y cuando Rilke da su versión de la creación poética diciendo que los "versos no son sentimiento, como creen muchos, sino experiencias", Mariátegui reconoce que este "juicio es fundamental romántico e individualista. Supone que la obra del poeta se alimenta exclusivamente de su experiencia personal" pero esto no lo hace menospreciar al poeta representante del individualismo. A Magda Portal la identifica como "la poetisa de ' $₫$ ternura" y dice que en "su poesía Magda nos da, ante todo, una límpida versión de sí misma. No se escamotea, no se mistifica, no se idealiza. Su poesía es su verdad" (255). Pero completa el círculo, como crítico, al admirar a Isadora Duncan y a Luisa Reissner como mujeres auténticamente revolucionarias: "Decadente, prerrafaelista, helenizante, refinada, en las varias estaciones de su arte, Isadora Duncan obedeció en su creación a un permanente impulso revolucionario" (215). De Larisa Reissner dice que colaboró con Lunatcharsky en los primeros meses de la revolución soviética a salvar los tesoros artísticos de Rusia, y luego se marchó a ocupar un puesto en el frente. "Fue una Juana de Arco proletaria, que milagrosamente escapó muchas veces a la muerte en manos de los enemigos de su fe. El Frente es el libro que recoge su testimonio de esta lucha" (215).

Esta capacidad de Mariátegui de ver el arte y la literatura desde perspectivas tan variadas sirve de ejemplo para entender cómo él pudo transcender las afiliaciones ideológicas como crítico literario. La amplitud en su pensamiento obviamente impresionó a don Joaquín y a sus colaboradores y lectores. Esto se ve en lo que los críticos decían en el Repertorio Americano acerca de Mariátegui como pensador y como director de su propia revista. Sin embargo, la impresión más impactante que quedó de Mariátegui en las páginas del Repertorio Americano fue la del director de Amauta perseguido por el gobierno peruano. 


\section{La imagen de Mariátegui y de Amauta en el Repertorio Americano}

Para el 13 de agosto de 1927, cuando los críticos y pensadores del Repertorio Americano comenzaron a prestarle atención a Mariátegui y a su obra, él ya había publicado quince artículos en la revista. Como se ha visto en este estudio, la mayoría de estos artículos eran sobre tres temas: el americanismo continental, la enseñanza y la literatura.

Los lectores del Repertorio Americano leen por primera vez acerca de Amauta en el número 20 de 1927, en el que se reproduce la "Carta de Unamuno a José Carlos Mariátegui”" 1 . Ésta termina con las siguientes palabras: "Gracias, amigo mío, y adentro con Amauta. Le desea a ésta vida fecunda aunque sea corta -revista que envejece, degenera-y a su Perú justicia en la libertad, Miguel de Unamuno" (316).

El 16 de julio de 1927, el Repertorio Americano publica una carta de Magda Portal que da el primer aviso acerca de la situación en la que se encuentra Mariátegui. En su carta, Portal opina que "El Repertorio Americano representa hoy el portavoz de la nueva conciencia de Latino-américa", y explica que por eso está enviando la protesta del grupo intelectual que en el Perú todavía se sentía "libre de la imposición conservadora y burguesa, por lo menos, espiritualmente" (47). Luego, en un tono alarmante, Portal anuncia al mundo la condición en que está Mariátegui después de haber sido arrestado como parte de un "complot comunista".

En este país la degeneración política llega a los últimos grados... [S]e inventa el bluff comunista comprometiendo a más de 300 personas, de las cuales más de 100 están en la isla de San Lorenzo, nueva Bastilla peruana: otros en inmundos calabozos: otros desterrados ya, sin que se sepa su rumbo, y lo que es más criminal, José Carlos Mariátegui, enfermo de gravedad, inválido de las dos piernas, encerrado en un calabozo en el hospital militar, sin ninguna atención médica, incomunicado, un hombre que no puede valerse por si mismo.-Creo que en el momento que le escribo, Mariátegui declara la huelga de hambre: esto quizás no lo transmitan los cables-pero es preciso gritarlo bien alto para que se conozca que en el Perú vulgares gamonales para sostenerse en la amistad del déspota Leguía, asesinan impunemente a los más notables intelectuales y obreros que tienen la osadía de no pensar como ellos (47). [Énfasis nuestro.]

Respondiendo al aviso de Portal y a la carta de Mariátegui, García Monge organiza una defensa a favor de Mariátegui. Estructura el número 6 del Repertorio Americano (13 de agosto, 1927) alrededor de su colega peruano, colocando en la primera página un artículo de Mariátegui sobre González Prada ${ }^{2}$ y una "Protesta" contra la clausura de Amauta. En su "Protesta", Mariátegui pide la solidaridad de García Monge y la de otros intelectuales en su lucha contra el gobierno peruano.

Usted, estimado compañero, conoce Amauta. Apelo a su imparcial testimonio para rechazar y condenar las acusaciones con que se pretende justificar la clausura de esta revista que representa un movimiento ideológico no sólo peruano sino continental. Invoco el juicio de los intelectuales honrados. De muchos he recibido ya generosas demostraciones de solidaridad que me honran y alientan (91).

\section{García Monge pronuncia su propia protesta:}

Es claro, Amauta no cabía en el ambiente asfixiante de Lima. Ya extrañábamos que lo dejaran llegar al Número 9. ...Si Amauta se ciñe a un programa de arte por arte y mera literatura, no se habrían metido con ella. Pero agitaba ideas...igran pecado en los países oprimidos de nuestra América! ...Téngasc de esta entrega del Repertorio como un homenaje a los altos méritos de José Carlos Mariátegui, como 
hombre y como escritor de vanguardia. El Repertorio se ha honrado ya con producciones de Mariátegui. ¡Y más que publicará! Mariátegui es una de las mentes curiosas, activas y vigilantes en esta hora trémula de la América española (93).

El número fechado el 27 de agosto de 1927 incluye también la correspondencia entre Mariátegui y representantes de revistas de la Argentina y Cuba. En una carta a Samuel Glusburg, director de Babel en Buenos Aires, Mariátegui afirma sus convicciones: "Soy revolucionario. ... Además, si la revolución exige violencia, autoridad, disciplina, estoy por la violencia, por la autoridad, por la disciplina" (125). García Monge opina que esta carta refleja la recia personalidad de Mariátegui (125); y Glusberg confirma que desde Buenos Aires él y los colaboradores de Babel (Horacio Quiroga, Leopoldo Lugones, Roberto J. Payro, Enrique Espinosa y Alberto Gerchunoff) telegrafiaron al gobierno peruano, pidiendo la libertad del amauta, mas el gobierno peruano contesta: "Mariátegui no está preso" (125).

En su protesta contra la clausura de Amauta, el grupo de la Revista de Avance describe a Mariátegui como "el líder inmaculado, austero, abnegado, de la juventud peruana que desde hace algún tiempo viene abonando doctrinalmente la conciencia pública del Perú con nueva ideología política, social y económica" (93). De aquí en adelante, esta será la imagen de Mariátegui que los grupos progresistas guardarán de él.

El ciclo de cartas sobre la clausura temporal de Amauta se cierra tres meses más tarde con la publicación de una carta de Mariátegui en la que agradece el apoyo de todos los que protestaron a su favor, y reconoce el papel importantísimo que el Repertorio Americano jugó como intermediario entre los defensores de Amauta y su director.

La protesta de Repertorio Americano, lo mismo que la de los intelectuales argentinos y uruguayos y la de 1927 y el "Grupo minorista" de Cuba, revela por fortuna que una gran parte de la intelectualidad de nuestra América se mantiene alerta contra el imperialismo y sus aliados. A todos los intelectuales que me han hecho llegar generosas palabras de solidaridad, quiero decir, por intermedio de Repertorio Americano mi reconocimiento y el de mis compañeros de Amauta ( 5 de noviembre, 1927, 258).

Promete seguir adelante con Amauta, y termina diciendo que "si al pesar del clamor de los mejores espíritus de Hispano-América, no se me escuchara, saldré del Perú, para establecer la revista en Buenos Aires o Montevideo" (258), promesa que su muerte prematura no le permitió llevar a cabo.

Las protestas de los intelectuales latinoamericanos no sólo protegieron a Mariátegui de los ataques del gobierno peruano sino también crearon la imagen hagiográfica que hasta hoy día se tiene de él. Carlos Sánchez Viamonte, por ejemplo, señala la "virtud apostólica" de Mariátegui y lo describe en términos casi religiosos, rodeado de sus discípulos:

Los jóvenes intelectuales y universitarios agrupados en torno de Mariátegui han llegado a ser sus compañeros, pero siguen siendo sus discípulos a través de una larga disciplina de perfeccionamiento individual y de colaboración solidaria, porque es obra de selección deparativa y enaltecedora, la que se requiere para marchar junto a tales maestros... (94).

También el propio cuerpo de Mariátegui comienza a mitificarse, como podemos ver en el siguiente comentario de la escritora costarricense Carmen Lyra: 
José Carlos Mariátegui, el valeroso escritor a quien le faltan sus dos piernas, languidece en una mazmorra, quizá muriéndose de hambre-según la noticia de Magda Portal. Recuerdo sus artículos publicados en el Repertorio Americano y los recogidos en el volumen La escena contemporánea, y me parece tener al frente, la figura espiritual que los escribiera, erguida y completa, serena y apasionada al mismo tiempo, figura que el Perú debiera colocarse con orgullo sobre su frente y no arrojar como la de un criminal a un calabozo (87). [Énfasis nuestro.]

\section{La presentación del autor de La escena contemporánea y de los Siete ensa- yos de interpretación de la realidad peruana}

En "Carlos Mariátegui y la nueva generación peruana" (13 de agosto, 1927), el primer artículo en el Repertorio Americano que presenta la contribución de Mariátegui en el contexto de los valores de su generación, Antenor Orrego describe La escena contemporánea como un libro "palpitante porque ha nacido en la entraña viva del drama social a que asistimos en nuestra época" (86). Para entender el libro, dice Orrego, hay que saber que "Mariátegui es el hombre nuevo; es la nueva generación moceril que ... se dirige al Perú nuevo y ... representa una docencia de porvenir" (86).

Explica Orrego que ha querido "hablar más del hombre que del libro porque éste no se comprende sin aquél y sobre todo porque lo que más necesitamos es la presencia magnética de vidas ejemplares, docencia de carne viva y no aquella libresca, fría y estéril de pupitre universitario..." (86). Con estas palabras, Orrego revela la confianza incondicional que los críticos de su época tenían en el poder personal de los escritores quienes, se pensaba, podían controlar el proceso histórico por la manera en que organizaban su vida. Esta ideología llevaba a los críticos a enfocarse en la información biográfica del autor con la idea de que, por medio de esta aproximación, se entendía mejor la obra.

Sin embargo, otros comentaristas usaron diferentes perspectivas al aproximarse a la obra de Mariátegui. En 1929, el Repertorio Americano publicó otras perspectivas diferentes acerca de Los siete ensayos de interpretación de la realidad peruana (1928), el libro que definitivamente establece a Mariátegui como uno de los pensadores más originales de su época. Luis Valcárcel se enfoca en el aspecto indigenista de los Siete ensayos y dice que: "Como muy pocos indigenistas, Mariátegui entiende el problema indígena, y coincide con cuantos sostenemos que 'la cuestión del indio, más que pedagógica, es económica, es social'" (200). Como marxista, Esteban Pavletich cuestiona la ortodoxia de Mariátegui. Y para B. Sanin Cano: "El problema indígena es apenas una parte si bien la más considerable y original de su obra" (177). Como se puede ver, en solo cuatro años, tanto por sus propias contribuciones como por lo que los críticos decían de él, la imagen de Mariátegui en el Repertorio Americano cambió de defensor de la cultura europea a campeón de lo nacional.

\section{Homenajes después de la muerte de Mariátegui}

La muerte de Mariátegui el 16 de abril de 1930 desconsuela a sus admiradures, e inmediatamente después de su muerte, las revistas progresistas le dedican homenajes en los que se expresa una inmensa admiración hacia un héroe verdadero. García Monge le dedic número 20 de su revista, fechado el 24 de mayo de 1930; y como parte de su propio elogio 
incluye las siguientes palabras emocionantes en la primera página, debajo de una foto de Mariátegui dedicada a "Don Joaquín".

Murió en Lima en el pasado abril. ¡Cómo duele que se nos haya ido tan clara y perspicaz inteligencia! Del Rep. Am. fue amigo y estimador. Con su colaboración lo honró a veces. Estaba bien correspondido de parte nuestra. Nos asociamos al dilatado clamor de las juventudes intelectuales y obreras de nuestra América que lo han visto irse, y lo lloran (305).

Entre el 24 de mayo y el 25 de octubre de 1930, El Repertorio Americano publica numerosos elogios a Mariátegui de sus admiradores por todo el continente. Como parte del homenaje peruano, J. Eugenio Garro escribe: "Mariátegui, pobre, enfermo, débil orgánicamente, supo afirmar su fe con valentía, supo propulsarla con desenfado, con violencia; según frase propia: "metió toda su sangre para comunicarle pasión a sus ideales", y esto, ¡en qué hora!" (309). Del homenaje argentino resaltan las palabras de Luis Franco: "Ha muerto cuando comenzaba a ser indispensable" (344). Jorge Mañach lo recuerda "como un nombre dramático en un coro de hombres trágicos. Afirmó mientras dudaban. De ahí su fuerza" (121).

Fiel al admirado colega peruano, García Monge no deja que desaparezca la memoria de Mariátegui de las páginas de su revista, y en el primer aniversario de su muerte publica las siguientes palabras de David Alfaro Siquieros, quien elogia a Mariátegui desde la perspectiva de un compañero ideológico:

\begin{abstract}
Valientemente tomó su puesto como combatiente en las filas del proletariado revolucionario. Sujetó por entero su ideología y su acción, a la disciplina del partido que organizara Lenin y del cual fue no solamente uno de sus mejores teóricos, sino también el agitador y organizador directo de las masas trabajadoras del Perú.

A diferencia de la inmensa mayoría de los intelectuales izquierdizantes (muy numerosos en la América Latina), el intelectual Mariátegui, como Julio Antonio Mella, no se limitó a ver los toros desde la barrera sino que marcó el paso bravamente con los trabajadores en su penosa marcha ascendente de todos los días. Esa actitud suya explica fundamentalmente la fuerza de su obra ideológica, expuesta en diversos libros y continuadamente en su revista Amauta. Su obra constituye así la aportación más trascendental en deducciones y conclusiones Marxisto-Leninistas para la aplicación de la lucha revolucionaria en la realidad de los países de la América Latina (287).
\end{abstract}

En abril de 1940, en el décimo aniversario de la muerte de Mariátegui, García Monge le dedica el número 11 de la revista, colocando en la primera página la pintura de Mariátegui de Julia Codesido. Cinco colaboradores contribuyen al homenaje, entre ellos Waldo Frank y Blanca Luz Brum, dos amigos del círculo íntimo de Mariátegui. Enrique Espinoza recuerda Amauta y a su director, diciendo que: "Hay revistas que valen por la calidad de sus colaboradores o la inteligente disposición de sus materiales, y revistas cuyo más alto mérito está en el trabajo asiduo de su director. No tenemos por qué repetir que Amauta era de estas últimas, puesto que ya aseguramos que valía sobre todo por el aporte personal de Mariátegui" (161). En el mismo número, don Joaquín publica por primera vez dos reseñas de Mariátegui, sobre Indología de José Vasconcelos y L'agonie du Christhianisme [sic]. En una nota indica que había estado guardando estos dos manuscritos desde 1925, lo que también nos da una imagen del despacho del director. Sobre todo, nos 
da una idea del cariño y de la admiración que le tuvo al amigo peruano que jamás conoció en persona.

Quince años más tarde, para conmemorar el aniversario de los veinticinco años de la muerte de Mariátegui, la revista de nuevo dedica no solo su primera página a Mariátegui sino gran parte del número de marzo-abril de 1955. En una página y media se publican apuntes biográficos y bibliográficos, que incluyen, además de los dos libros publicados en vida de Mariátegui, las obras que, para entonces, sus hijos habían recopilado en Lima: El alma matinal y otras estaciones del hombre de hoy y Defensa del marxismo. Se anuncia la publicación de El artista y la época y otras obras inéditas por publicar: Historia de la crisis mundial, Figuras y aspectos de la vida mundial y Signos y obras. Un anuncio comercial promueve la venta del libro más reciente de Mariátegui, La novela y la vida.

Así fue que a través de los años, se reflejó en el Repertorio Americano el respeto y la admiración que Joaquín García Monge y los colaboradores de su revista le tenían a Mariátegui. Por casi treinta años después de su muerte, la revista costarricense siguió instruyendo a nuevas generaciones en los valores que siempre se promovieron en sus páginas, a las que Mariátegui contribuyó consistentemente por cinco años con artículos acerca del americanisnì continental, de la enseñanza y del papel de los artistas, especialmente de los escritores, como formuladores de la cultura nacional.

Al pasar los años, se mantuvo vivo el diálogo entre los colaboradores del Repertorio Americano, mostrando a través de esta dinámica la importancia de las redes informales que, según Pierre Bourdieu, es una de las estrategias en el campo de la producción cultural (121), una dinámica que da una autoridad cultural a los esfuerzos colectivos y establece en escrito la ideología de un grupo.

Por casi cuarenta años, Joaquín García Monge, el infatigable director del Repertorio Americano juntó en las páginas de su semanario las palabras de todos los líderes sociales y artísticos de su escena contemporánea, captando, a su manera, la evolución de la ideología progresista en la América Latina. Con sus tijeras y su goma, con el esfuerzo de un creyente en lo americano, recopiló imágenes de los pensadores y creadores más sobresalientes de su época. Entre ellos, uno de los más inolvidables fue José Carlos Mariátegui.

\section{Notas}

La investigación para este trabajo se hizo en 1997 en la Benson Latin American Collection de la Universidad de Texas en Austin, y en el Departamento de Colecciones Especiales de la M.D. Anderson Library de la Universidad de Houston. Ambas bibliotecas cuentan con la colección completa del Repertorio Americano. Al transcurso de la larga vida del Repertorio Americano, la Benson Latin American Collection mantuvo una subscripción a la revista. La M.D. Anderson Library compró la colección entera. No se han mantenido datos acerca de esta adquisición.

1. Esta carta de Unamuno había aparecido en el número 5 de Amauta (enero de 1927). Se reimprime en el Repertorio Americano el 28 de mayo de 1927.

2. Mariátegui incorpora este artículo sobre González Prada al séptimo ensayo, "El proceso de la literatura", de los Siete ensayos de interpretación de la realidad peruana. 


\section{Bibliografía}

1927, Revista de Avance. 1927. "Mariátegui, Amauta". Repertorio Americano XV, 6 (13 de agosto): 93.

Anónimo. 1940. "Maestros indoiberos: García Monge". Repertorio Americano. XXXVII, 6 (16 de marzo): 85-6. [Reimpreso de El Nacional, México, D.F., 3 de diciembre, 1939].

Araquistain, Luis. 1925. "Organización de la cultura hispánica”. Repertorio Americano. X, 17 (6 de julio): 260-1.

Bourdieu, Pierre. 1993. The Field of Cultural Production. Randall Johnson, redactor. New York: Columbia University Press.

brenes Mesén, R. 1927. "El Repertorio Americano". Repertorio Americano. XIV, 6 (12 de febrero): 93 .

Cardona Peña, Alfredo. 1983. "Prólogo: Joaquín García Monge en sus cartas". Índice General del Repertorio Americano. Tomo F-H, lv-lxxii. Evelio Echevarría (comp.).

Creedman, Theodore. 1991. Historical Dictionary of Costa Rica. Latin American Historical Dictionaries. No. 16. Metuchen, N.J. \& London: The Scarecrow Press.

Echevarría, Evelio (comp.). 1981. Índice General del Repertorio Americano. Tomo A-B. San José: Editorial Universidad Estatal a Distancia.

1981. Índice General del Repertorio Americano. Tomo C-E. San José: Editorial Universidad Estatal a Distancia.

1983. Índice General del Repertorio Americano. Tomo F-H. San José: Editorial Universidad Estatal a Distancia.

Elmore, Edwin. 1925. "Carta a José Carlos Mariátegui: Congreso Libre Ibero-americano de Intelectuales". Repertorio Americano. X, 17 (6 de julio): 259-60.

1925. "Carta al señor don Alberto Zum Felde de Edwin Elmore". Repertorio Americano. X, 5 (30 de marzo): 70-1.

1925. "Cartas abiertas: A propósito del Congreso intelectual hispanoamericano". Repertorio Americano. X, 11 (18 de mayo): 162-4.

1925. "Declaración aprobada por unanimidad en la segunda reunión de Montevideo, efectuada el 6 de febrero en el Círculo de la Prensa". Repertorio Americano. X, 5 (30 de marzo): 71. 
1925. "Primer Congreso Iberoamericano de Intelectuales". Repertorio Americano. X, 5 (30 de marzo): 65-7.

Espinoza, Enrique. 1940. "En el décimo aniversario de la muerte de José Carlos Mariátegui". Repertorio Americano. XXXVII, 11 (20 de abril): 161-2, 175.

Ferrer, Luis. 1981. "Prólogo: Don Joaquín y el arte". Índice General del Repertorio Americano. Tomo C-E, xxxix-xlvii. Evelio Echevarría (comp.).

Flores, Ángel. 1992. Spanish American Authors: The Twentieth Century. New York: The H.W. Wilson Company.

Franco, Luis. 1930. "Del homenaje argentino a Mariátegui". Repertorio Americano. XX, 22 (14 de junio): 344-7.

García Monge, Joaquín. 1955. "El 16 de abril se cumplirán 25 años de la muerte de José Cái los Mariátegui”. Repertorio Americano. XLIX, 3 (marzo y abril): 34-5.

1927. "Protesta". Repertorio Americano. XV, 6 (13 de agosto): 93.

Garro, J. Eugenio. 1930. "Del homenaje peruano a José Carlos Mariátegui". Repertorio Americano. XX, 20 (24 de mayo): 308-10.

Garrón de Doryan, Victoria (ed.). 1971. Joaquín García Monge. San José: Ministerio de Cultura, Juventud y Deportes. Departamento de Publicaciones.

Henríquez Ureña, Max. 1959. "Un apóstol de la cultura: García Monge”. Repertorio Americano. L: Número Extraordinario in Memoriam: 88-9.

Klaiber, Jeffrey L. 1975. "The Popular Universities and the Origins of Aprismo, 1921-1924”, Hispanic American Historical Review. LV, 4 (noviembre): 693-715.

Leguía, Jorge Guillermo. 1926. "García Monge y el Repertorio Americano". Repertorio Americano. XIII, 17 (6 de noviembre): 259-61.

Lugones, Leopoldo. 1925. "Política americana". Repertorio Americano. X, 5 (30 de marzo): 65- 7.

Lyra, Carmen. 1927. “José Carlos Mariátegui”. Repertorio Americano. XV, 6 (13 de agosto): 87.

Mariátegui, José Carlos. 1927. "Babel, de Buenos Aires, y Mariátegui”. Repertorio Americano. $\mathrm{XV}, 8$ (27 de agosto): 125 .

1927. “Carta de Mariátegui”. Repertorio Americano. XV, 17 (5 de noviembre): 257-8. 
1928. "Denunciando calumnias". Repertorio Americano. XVII, 9 (1 de septiembre): 139.

1929 "Dos libros, dos mujeres: Las memorias de Isadora Duncan y Hombres y máquinas por Larisa Reissner". Repertorio Americano. XIX, 14 (12 de octubre): 214-5.

1925. “¿Existe un pensamiento hispano-americano?”. Repertorio Americano. X, 17 (6 de julio): $257-8$.

1926. "El artista y la época". Repertorio Americano. XIII, 24 (25 de diciembre): 380-1.

1927. “González Prada”. Repertorio Americano. XV, 6 (13 de agosto): 81-4.

1929. "Magda Portal”. Repertorio Americano. XIX, 16 (26 de octubre): 255-6.

1928. "Noticia de libros: Los Artamonov". Repertorio Americano. XVII, 9 (1 de septiembre): 142 .

1927. "Protesta". Repertorio Americano. XV, 6 (13 de agosto): 91.

1929. "Preludio del elogio de El cemento y del realismo proletario". Repertorio Americano. XIX, 20 (23 de septiembre): 317-8.

1925. "¿Qué hora es? ...La escuela laica”. Repertorio Americano. XI, 1 (7 de septiembre): $13-4$.

1926. “¿Qué hora es? ...La enseñanza y la economía”. Repertorio Americano. XII, 9 (1 de marzo): 142-3.

1925. “¿Qué hora es? ...La libertad de la enseñanza”. Repertorio Americano. XI, 9 (9 de noviembre): 136-7.

1928. “¿Qué hora es? ...Los maestros y las nuevas corrientes”. Repertorio Americano. XVI, 5 (4 de febrero): 78-9.

1928. "Rainer María Rilke”. Repertorio Americano. XVII, 9 (1 de septiembre): 139. 1926. “Romain Rolland”. Repertorio Americano.. XIII, 21 (4 de diciembre): 329-30. 1926. "Waldo Frank". Repertorio Americano. XII, 21 (5 de junio): 329. Masiello, Francine. 1985. "Argentine Literary Journalism: The Production of a Critical Discourse”. Latin American Research Review. XX (1): 27-60. 
1993. "Rethinking Neocolonial Esthetics: Literature, Politics, and Intellectual Community in Cuba's Revista de Avance". Latin American Research Review. XXVIII (2): 3-31.

Nieto Caballero, L.E. 1929. "García Monge”. Repertorio Americano. XIX, 15 (19 de octubre): 234.

Orrego, Antenor. 1927. "Carlos Mariátegui y la nueva generación peruana". Repertorio Americano. XV, 6 (13 de agosto): 86-7.

Pavletich, Esteban. 1926. "Con Diego Rivera: el artista de una clase". Repertorio Americano. XIII, 11 (18 de septiembre): 168-71.

1929. "7 ensayos en busca de una realización”. Repertorio Americano. XVIII, 14 (13 de abril): 221-3.

Portal, Magda. 1927. "El problema de Indoamérica y el complot comunista". Repertorio Americano. XV, 14 (22 de octubre): 233-5.

1927. "Magda Portal pone al descubierto la fealdad de la tiranía que azota al Perú". Repertorio Americano. XV, 3 (16 de julio): 47-8.

Said, Edward. 1982. "Opponents, Audiences, Constituencies, and Community". Critical Inquiry. IX: 1-26.

Sánchez, Luis Alberto. 1959. “'Un tal García Monge’ ha muerto”. Repertorio Americano. L, Número Extraordinario in Memoriam: 86-87.

Sánchez Viamonte, Carlos. 1927. "La libertad de pensar, bajo la tiranía peruana". Repertorio Americano. XV, 3 (16 de julio): 94.

Sanín Cano, B. 1929. "Escritores universales en América: José Carlos Mariátegui”. Repertorio Americano. XIX, 12 (28 de septiembre): 177-8.

Silva Herzog, Jesús. 1983. "Una vida en la vida de México". Mis trabajos y los años. Tomo II. Citado por Alfredo Cardona Peña, lx-lxi.

Siqueiros, Alfaro David. 1931. "Mariátegui”. Repertorio Americano. XXII, 18 (16 de mayo): 287.

Unruh, Vicky. 1989. "Mariátegui's Aesthetic Thought: A Critical Reading of the Avant-Gardes". Latin American Research Review. XXI, 3: 45-69.

Valcárcel, Luis. 1929. "Un libro de Mariátegui”. Repertorio Americano. XVIII, 13 (6 de abril): 200-1. 


\section{Anexo 1}

\section{La presencia de José Carlos Mariátegui en el Repertorio Americano}

\section{Colaboraciones de José Carlos Mariátegui}

6 de julio, 1925

27 de julio, 1925

7 de septiembre, 1925

9 de noviembre, 1925

4 de enero, 1926

25 de enero, 1926

lero de marzo, 1926

8 de mayo, 1926

5 de junio, 1926

4 de diciembre, 1926

25 de diciembre, 1926

6 de agosto, 1927

6 de agosto, 1927

13 de agosto, 1927

13 de agosto, 1927

27 de agosto, 1927
“¿Existe un pensamiento hispano-americano?” X, 17: 257- 258.

"Un congreso más pan-americano que científico". X, 20:-310-311.

"¿Qué hora es?: Introducción a un estudio sobre el problema de la educación pública-La escuela laica". XI, 1: 13-14.

“QQué hora es?: La libertad de la enseñanza”. XI, 9: 136-137.

"Edwin Elmore". XII, 1: 3-4.

"José Ingenieros". XII, 4: 56-57.

“¿Qué hora es?: La enseñanza y la economía”. XII, 9: 142-143.

“QQué hora es?: Los maestros y las nuevas corrientes?” XII, 18: 273274.

"Waldo Frank". XII, 21: 329.

“Romain Rolland". XIII, 21: 329-330.

"El artista y la época". XIII, 24: 380-381.

“William J. Bryan". XV, 5: 72.

"Entendámonos" [Carta al Sr. Jaime Torres Bodet en protesta por un equívoco que éste hizo acerca de la posición de Amauta en cuanto al nacionalismo continental]. XV, 5: 79.

"González Prada". XV, 6: 81-84.

"Protesta" [Acerca de la clausura de Amauta]. XV, 6: 91.

"Babel, de Buenos Aires, y Mariátegui" [Una carta a Samuel Glusberg de José Carlos Mariátegui, quien agradece la protesta de Babel contra la clausura de Amauta, e invita a los colaboradores de Babel a colaborar con Amauta]. XV, 8: 125. 
5 de noviembre, 1927 “Carta de Mariátegui” [Agradecimiento a García Monge por los trabajos que Repertorio Americano publicó en protesta de la clausura de Amauta]. XV, 17: 257-258.

5 de noviembre, 1927 "Ramiro de Maeztu y la dictadura española". XV, 17: 264, 266.

4 de febrero, 1928 "Rainer María Rilke". XVI, 5: 78-79.

1 de septiembre, 1928 "Denunciando calumnias" [Sobre Gorki]. XVII, 9: 139.

1 de septiembre, 1928 "Noticia de libros: Los Artmonov de Maximo Gorki". XVII, 9: 142.

15 de diciembre, 1928 "Tablero, 1928: Los libros y folletos de la semana-7 ensayos de interpretación de la realidad peruana. Biblioteca Amauta. Lima, 1928. Advertencia del autor." XVII, 23: 365-366.

28 de septiembre, 1929 "Rusia y China". XIX, 12: 178-179.

12 de octubre, 1929 "Dos libros, dos mujeres: Las memorias de Isadora Duncan, y Hombres y máquinas de Larisa Reissner". XIX, 14: 214- 215.

26 de octubre, 1929 "Magda Portal" [De Siete ensayos de interpretación de la realidad peruana]. XIX, 16: 255-256.

23 de septiembre, 1929 "Preludio del elogio de El cemento y del realismo proletario" [Acerca de Fedor Gladkov]. XIX, 20: 317-318.

11 de octubre, 1930 "César Falcón: La verdadera solidaridad". XXI, 14: 216, 218-219.

20 de abril, 1940 "Dos artículos de Mariátegui: "Indología” por José Vasconcelos; y "Un nuevo libro de Unamuno: 'L'agonie du Christhianisme' [sic]". XXXXVII, 11: 164-166. [La revista nota que estos artículos se habían entregado al Repertorio Americano en 1925: "Hasta hoy, inéditos en este semanario".]

\section{Mariátegui: su vida y obra comentada por los escritores y los críticos}

28 de mayo, 1927

"Carta de Unamuno a José Carlos Mariátegui” [Acerca de Amauta]. XIV, 20: 312, 315-316.

16 de julio, $1927 \quad$ Magda Portal. "Magda Portal pone al descubierto la fealdad de la tiranía que azota al Perú”. XV, 3: 47-48. 
13 de agosto, 1927

13 de agosto, 1927

13 de agosto, 1927

13 de agosto, 1927

13 de agosto, 1927

27 de agosto, 1927

22 de octubre, 1927

Atenor Orrego. "Carlos Mariátegui y la nueva generación peruana". $\mathrm{XV}$, 6: 86-87.

Carmen Lyra. "José Carlos Mariátegui”. XV, 6: 87.

1927: Revista de Avance. "Mariátegui, Amauta". XV, 6: 93.

Joaquín García Monge. "Protesta". XV, 6: 93.

Carlos Sánchez Viamonte. "La libertad de pensar, bajo la tiranía peruana" [Acerca de la clausura de Amauta]. X, 6: 94.

Samuel Glusberg. "Babel, de Buenos Aires, y Mariátegui [Glusberg y los colaboradores de Babel protestan contra la clausura de Amauta en una carta reimpresa de Babel; con una carta de Mariátegui en la que agradece el apoyo]. XV, 8: 125.

Magda Portal. "El problema de Indoamérica y el complot comunista" [Un dibujo del APRA, hecho por el artista mexicano Balmori, acompaña a este artículo. El dibujo ya había aparecido en Amauta II, 9 (mayo, 1927): 11] XV, 14: 233-235.

10 de diciembre, 1927 Antonio Gallo. "La amistad de Frank y Mariátegui: A propósito de la visita de W. Frank a la Argentina”. XV, 22: 340-341.

30 de junio, $1928 \quad$ Blanca Luz Brum. "Recordando a Mariátegui" [Sobre la clausura de Amauta]. XVI, 24: 376.

6 de abril, 1929

Luis Valcárcel. "Un libro de Mariátegui: 7 ensayos de interpretación de la realidad peruana". XVIII, 13: 200-201.

6 de abril, 1929

Esteban Pavletich. "7 ensayos en busca de una realización". XVIII, 14: 221-223.

28 de septiembre, 1929 B. Sanín Cano. "Escritores universales en América: José Carlos Mariátegui”. XXIX, 12: 177-178.

14 de julio, 1934

Carlos Manuel Cox. "Reflexiones sobre José Carlos Mariátegui". XXIX, 2: 17-19.

20 de abril, $1940 \quad$ Blanca Luz Brum. "José Carlos Mariátegui recordado por Armando Bazán”. XXXVII, 11: 168.

6 de junio, 1942

Antonio Gallo. "La amistad de Frank y Mariátegui". XXXIX, 11: 169. 
25 de julio, 1942

25 de julio, 1942

marzo y abril, 1955

marzo y abril, 1955
Alberto Tauro. "José Carlos Mariátegui ante la génesis y misión de Amauta ". XXXIX, 16: 248.

Alejandro Manco Campos. "Tres personajes disímiles y representativos en el Perú" [Sobre José María Eguren, José Carlos Mariátegui y César Vallejo]. XXXIX, 16: 249-250. [Número dedicado a la literatura peruana, en el 121 aniversario de su independencia.]

“Obras de José Carlos Mariátegui”. XLIX, 3: 37.

"Un libro nuevo...José Carlos Mariátegui: La novela y la vida". XLIX, 3: 38 .

\section{Homenajes a Mariátegui}

24 de mayo, 1930

Rafael Maluenda. "José Carlos Mariátegui: El escritor--Maestro d’e energías morales.-Una gran fuerza psíquica.-La revista Amauta". XX, 20: 305-307.

24 de mayo, 1930

"Del homenaje peruano a José Carlos Mariátegui" [Enrique Bustamente y Ballivián, Raúl Porras Barrenechea, Luis Alberto Sánchez, José Diez-Canseco, J. Eugenio Garro, Jorge Basadre, Fabio Camacho]. XX, 20: 308-310.

14 de junio, 1930

"Del homenaje argentino a Mariátegui" [Leopoldo Lugones, Luis Franco, Arturo Capdevila, Alberto Gerchunoff, Enrique Méndez Calzada, Horacio Quiroga]. XX, 22: 344-347.

23 de agosto, 1930

"Del tributo cubano a José Carlos Mariátegui" [Juan Marinello y Jorge Mañach]. XXI, 8: 121, 123.

6 de septiembre, 1930

"Del tributo cubano a José Carlos Mariátegui: Hombre de letra viva" [Félix Lizaso y Francisco Ichaso]. XXI, 9: 142, 144.

25 de octubre, $1930 \quad$ Alberto Guillén. "Epístola irónica y sentimental a José Carlos Mariátegui (poema)." XXI, 17: 255-256.

16 de mayo, 1931

Alfaro David Siqueiros. "Mariátegui”. XX, 18: 287. [El dibujo que aquí se atribuye a Siqueiros antes se había atribuido a César Miró cuando había acompañado a un comentario de Blanca Luz Brum en Repertorio Americano . XVI: 24 (30 de junio, 1928): 376.]

20 de abril, 1940

Enrique Espinoza. "En el décimo aniversario de la muerte de José Carlos Mariátegui”. XXXVII, 11: 161-162, 175. 
20 de abril, 1940

"Del homenaje argentino a José Carlos Mariátegui: Fragmentos" [Reimpresión de los comentarios de Leopoldo Lugones, Horacio Quiroga, Arturo Capdevilla, Alberto Gerchunoff, Luis Franco, Ezequiel Martíntez Estrada, Waldo Frank]. XXXVII, 11: 163.

20 de abril, 1940

Waldo Frank. "Una palabra sobre Mariátegui”. XX, 11: 163- 164.

marzo y abril, 1955 Dardo Cúneo. "Noticia conmemorativa sobre José Carlos Mariátegui (1930-1955)". XLIX, 3: 33-34.

marzo y abril, 1955 "El 16 de abril se cumplirán 25 años de la muerte de José Carlos Mariátegui: Apuntes autobiográficos". XLIX, 3: 34-35. 
